\title{
Effect of dietary fibre of barley variety 'Rihane' on azoxymethane-induced aberrant crypt foci development and on colonic microbiota diversity in rats
}

\author{
Lamia Lahouar ${ }^{1}$, Philippe Pochart ${ }^{2}$, Hichem Ben Salem ${ }^{3}$, Mouledi El Felah ${ }^{4}$, Moncef Mokni ${ }^{5}$, \\ Fabien Magne ${ }^{2}$, Irène Mangin ${ }^{2}$, Antonia Suau ${ }^{2}$, Ester Pereira ${ }^{2}$, Mohamed Hammami ${ }^{6}$ and Lotfi Achour ${ }^{1 *}$ \\ ${ }^{1}$ Unité de recherche 03/UR/09-01 "Génome, Diagnostic Immunitaire et valorisation" (Institut Supérieur de Biotechnologie de \\ Monastir), Rue Tahar Hadded, BP 74, Monastir 5019, Tunisia \\ ${ }^{2}$ Laboratoire de Biologie, EA 3199, CNAM, 2 rue Conté, 75003 Paris, France \\ ${ }^{3}$ Laboratoire des Productions Animales et Fourragères, INRA-Tunisia, 2049 Ariana, Tunisia \\ ${ }^{4}$ Laboratoire des Grandes Cultures, INRA-Tunisia, 2049 Ariana, Tunisia \\ ${ }^{5}$ Service d'Anatomies Pathologiques à l'hôpital Farhat Hachad, Sousse-Tunisia, Tunisia \\ ${ }^{6}$ Laboratoire de Biochimie, UR 08/39 'Nutrition Humaine et Désordres Métaboliques', Faculté de Médecine de Monastir, Tunisia
}

(Submitted 21 June 2011 - Final revision received 16 December 2011 - Accepted 4 January 2012 - First published online 14 March 2012)

\begin{abstract}
Many epidemiological and experimental studies have suggested an important role for dietary fibre (DF) of cereals in the prevention of colon cancer. The objective of the present study was to explain the effects of the DF of barley Rihane (BR) on azoxymethane (AOM)induced aberrant crypt foci (ACF) and colonic bacterial diversity in rats. Following an acclimatisation period, rats were divided into four groups and fed a control (C) diet or experimental diet containing $30 \%$ of BR. DF content in the experimental diet was twice that of the C diet (total DF was $8.69 \%$ in the $\mathrm{C}$ diet and $15.24 \%$ in the BR diet). At 7 and 8 weeks of age, rats received two successive subcutaneous injections of AOM at $20 \mathrm{mg} / \mathrm{kg}$ body weight. At 12 weeks after the first injection, ten animals from each group were killed. The BR diet decreased colonic $\mathrm{pH}(P<0.05)$ compared with the $\mathrm{C}$ diet. The total number of ACF observed decreased considerably in the BR/AOM group compared with the $\mathrm{C} / \mathrm{AOM}$ group $(P<0 \cdot 05)$. Comparison of similarity coefficients showed variability of colonic microbiota species between the different groups. In addition, we showed inter-individual variability within the same group. This similarity was affected by BR and AOM. The present results show that bifidobacteria numbers were lower in rats fed the BR diet compared with those fed the $\mathrm{C}$ diet. However, the number of enterobacteria in colonic content was increased $(P<0.05)$ in the BR group compared with the $\mathrm{C}$ group. The results from the present study show that the DF of BR reduced the incidence of AOM-induced ACF and increased microbiota biodiversity.
\end{abstract}

Key words: Barley variety 'Rihane': Aberrant crypt foci: Colonic microbiota: Temporal temperature gradient gel electrophoresis: Real-time PCR

The potential for whole grains to lower the risk of colorectal cancer is recognised. This effect could be attributed to dietary fibre $(\mathrm{DF})^{(1)}$. Barley (Hordeum vulgare L.) is an interesting source of DF. It is an ancient cereal grain, which upon domestication has evolved from largely a food grain to a feed and malting grain ${ }^{(2)}$. However, barley food use today remains important in some cultures around the world, particularly in Tunisia, which is the second centre of diversity for barley. In Tunisia, barley is used for both feed (85\%) and food $(15 \%)^{(3)}$. Barley soup, barley bread and 'malthouth' are probably the main endemic barley-based food processed from barley grain in the region. Rihane, a Tunisian barley variety, officially registered in 1987 , has contributed significantly to the increase in barley national production in Tunisia, and it is cultivated in Morocco, Algeria, Libya, Lebanon, Iraq, Iran, Afghanistan, Cyprus and China ${ }^{(3)}$. Animal models of chemically induced colon cancer may provide a useful tool in identifying potentially preventive dietary strategies and in helping to better understand the mechanisms by which protection might be achieved. The effect of DF on the reduction in colon cancer has been attributed to increased faecal bulk, dilution of potential carcinogenic compounds and fermentation by colonic anaerobic bacteria to produce $\mathrm{SCFA}^{(4,5)}$. The rat azoxymethane (AOM) model of colon cancer is used for this purpose ${ }^{(6)}$. AOM is a metabolite of the procarcinogen 1,2-dimethylhydrazine, and is one metabolic step closer to the proximate carcinogen capable of inducing colonic aberrant crypt and colon tumours (adenomas and adenocarcinomas) ${ }^{(7)}$.

Abbreviations: ACF, aberrant crypt foci; AOM, azoxymethane; BR, barley 'Rihane'; C, control; DF, dietary fibre; $D_{\mathrm{sc}}$, Dice's similarity coefficient; RF, relative front; TTGE, temporal temperature gradient gel electrophoresis.

*Corresponding author: L. Achour, fax +216 73465 404, email lotfiachour@yahoo.fr 


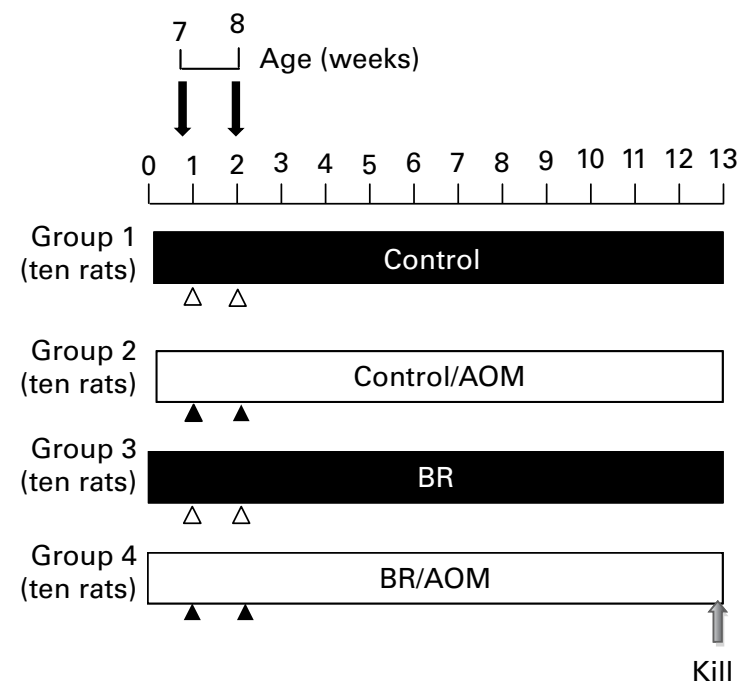

Fig. 1. Experimental design. $\Delta$, Saline; $\boldsymbol{\Lambda}$, subcutaneous injection of azoxymethane (AOM) at $20 \mathrm{mg} / \mathrm{kg}$ body weight. BR, barley Rihane.

and fixed in $10 \%$ formalin $(\mathrm{v} / \mathrm{v})$ overnight, and prepared for haematoxylin and eosin staining. The number of ACF in each group was quantified. ACF were identified as rounded and defined clusters of crypts, where the crypt sizes are polymorph and greater than normal and the luminal sizes are also polymorph.

The classification of ACF from each group was also assessed for the presence and degree of dysplasia according to the criteria described previously by Papanikolaou et al. ${ }^{(14)}$. The criteria for the assessment of the degree of dysplasia are described as follows:

(1) Mild to moderate dysplastic foci:

(a) Crypts have greater increased crypt height and more dilation of the crypt.

(b) Cells exhibit moderately enlarged nuclei with irregular location, orientation, shape and darker colour with some focal nuclear stratification and slight vesiculation with no mitotic bodies observable.

(c) There is a greater loss of the cytoplasm.

(d) Crypts are moderately basophilic and more hypercellular.

(2) Moderate to severe dysplastic foci:

(a) Crypts have increased height with severe dilation.

(b) Cells exhibit enlarged nuclei with irregular location, loss of cell polarity, abnormal colour and shapes, some pleomorphism, extensive stratification and more vesiculation with prominent or multiple nucleoli.

(c) Crypts are strongly basophilic and very hypercellular.

\section{Extraction and purification of total DNA}

DNA was extracted from colon samples (125 mg) using a bead-beating method adapted from Godon et al. ${ }^{(15)}$. The protocol has been described in detail in a previous study ${ }^{(16)}$. The amount and integrity of DNA were estimated using $2 \%$ $(\mathrm{w} / \mathrm{v})$ agarose gel electrophoresis containing ethidium bromide $(0 \cdot 1 \mathrm{ng} / \mathrm{ml})$, in $1 \times$ Tris-Borate-EDTA (Sigma Chemical Company).

\section{Bacterial temporal temperature gradient gel electrophoresis}

The colonic microbiota of rats were analysed using temporal temperature gradient gel electrophoresis (TTGE). The primers S-D-Bact-339-a-S-20 (50-CTC CTA CGG GAG GCA GCA GT30) and S-D-Bact 788-a-A-19 (50-GGA CTA CCA GGG TAT CTA A-30) were used to amplify the variable regions 3 and 4 of the bacterial $16 \mathrm{~S}$ ribosomal RNA genes. A GC-rich sequence (50-CCC CCC CCC CCC CGC CCC CCG CCC CCC GCC CCC GCC GCC C-30) was added to the $5^{\prime}$ end of the primer S-DBact-788-a-A-19, as described previously by Magne et al. ${ }^{(16)}$. The DCode universal mutation detection system (Bio-Rad) was used for sequence-specific separation of amplicons. Additionally, known bacterial strains were used to standardise band migration and gel curvature among different gels. This ladder consisted of the following organisms listed in their migration order: Bacteroides sp., Prevotella sp., Enterococcus faecium, Staphylococcus epidermidis, Escherichia coli and Bifidobacterium longum ${ }^{(17)}$.

TTGE analysis was based on the method of Deplancke et $a l .{ }^{(18)}$. Gel patterns were analysed using Diversity Database 2.1 Discovery Series (Bio-Rad).

Bands were detected automatically. Each band was defined through its relative intensity and relative front (RF). Relative intensity was the intensity of a particular band in a lane expressed as a percentage of the total intensity data in the lane. The $\mathrm{RF}$ was the distance from the top of a defined lane to the band. In order to compare several gels, a normalised RF derived from the RF was used to classify the bands. This normalised RF was based on the migration of a marker. A band set stored classified the bands defined as unique band types according to their normalised RF.

Comparisons of TTGE profiles were performed using Dice's similarity coefficient $\left(D_{\mathrm{sc}}\right)$ analysis based entirely on the results of band classification. $D_{\mathrm{sc}}$ values were compared, based on the presence or absence of bands. Dice's coefficient is defined as follows

$$
D_{\mathrm{sc}}=(2 j /(a+b)),
$$

where $j$ is the number of common bands between samples $\mathrm{A}$ and $\mathrm{B} ; a$ and $b$ are the total number of bands in samples $\mathrm{A}$ and $\mathrm{B}$, respectively. This coefficient ranges from 0 (no common bands) to 1 (identical band patterns). Consequently, the distance between two TTGE profiles was as follows ${ }^{(17)}$ : distance $=1-D_{\mathrm{sc}}$.

\section{Real-time PCR for bacterial quantification}

Reactions were performed in duplicate in a fixed volume $(25 \mu \mathrm{l})$ within ninety-six-well twin-tech PCR plates, using the Platinum SYBR Green qPCR SuperMix-UDG (Invitrogen). 
The forward and reverse primers used were Bif164f and Bif662r for Bifidobacterium ${ }^{(19)}$, Ent1113f and Ent1418r for enterobacteria and Bia339f and Bia788 $\mathrm{r}$ for bacteria ${ }^{(17)}$. Amplifications were performed in a Mastercycler ep Realplex ${ }^{4}$ (excitation source $470 \mathrm{~nm}$, emission $520 / 550 \mathrm{~nm}$; Eppendorf AG) with the following temperature profile: one cycle at $52^{\circ} \mathrm{C}(2 \mathrm{~min})$, one cycle at $96^{\circ} \mathrm{C}(2 \mathrm{~min})$, forty cycles of denaturation at $96^{\circ} \mathrm{C}(15 \mathrm{~s})$, primer annealing at $62^{\circ} \mathrm{C}(1 \mathrm{~min})$ for bifidobacteria and for enterobacteria and at $55^{\circ} \mathrm{C}(1 \mathrm{~min})$ for total bacteria, and elongation step at $68^{\circ} \mathrm{C}(2 \mathrm{~min})$. The melting curve was obtained by slow heating at temperatures from 60 to $96^{\circ} \mathrm{C}$ at a rate of $0 \cdot 2^{\circ} \mathrm{C} / \mathrm{s}$ with continuous fluorescence collection. A negative control and a positive control were included on each plate. Each assay was performed in duplicate in the same run. The cycle threshold $\left(C_{\mathrm{t}}\right)$ was calculated as the cycle number at which the reaction became exponential. Standard curves were constructed using plasmid containing 16S ribosomal DNA fragments amplified with corresponding primers. The plasmid concentration was measured using a QubitTM fluorimeter (Invitrogen) according to the manufacturer's instructions.

\section{Statistical analyses}

Data are presented as mean values with their standard errors. Statistical analysis was performed using STATVIEW 4.0. Two-way ANOVA was used to determine the effects of the $\mathrm{DF}$ of $\mathrm{BR}, \mathrm{AOM}$ and their interaction. A mean difference is considered significant when $P<0.05$.

\section{Results}

\section{Effect of the diet on food intake and weight body in} azoxymethane-treated rats

The diet was well accepted by the rats. No mortality was caused by the diet or AOM. The final body weights and food intake for each group are shown in Table 3. The final body weight was lower $(P<0.05)$ in the BR group compared with the $\mathrm{C}$ group. The growth rate of rats was slower
$(P<0.05)$ in the $\mathrm{BR}$ and $\mathrm{BR} / \mathrm{AOM}$ groups compared with the $\mathrm{C}$ group. Food intake was not affected by dietary treatments.

\section{Effect of the diet on colon, colon content, colonic wall weights and colonic $\mathrm{pH}$ in azoxymethane-treated rats}

The colon, colon digesta and colonic wall weights for each group are shown in Table 3. BR induced a significant increase in colon weight $(P<0.05)$ compared with the $\mathrm{C}$ group. In the same way, this variety significantly increased colon weight even in the presence of AOM. The colon digesta was $(P<0.05)$ lower in the $\mathrm{C} / \mathrm{AOM}$ group than in the $\mathrm{C}$ group, whereas $\mathrm{BR}$ induced an increase $(P<0.05)$ in colon digesta compared with the $\mathrm{C}$ group. The colonic wall was thickened $(P=0.03)$ in rats fed the $\mathrm{BR}$ diet than in the $\mathrm{C}$ group, while it was thinner in the $\mathrm{C} / \mathrm{AOM}$ group $(P<0.05)$. BR increased the colonic wall $(P<0.05)$ even in the presence of AOM.

Colonic $\mathrm{pH}$ was $(P<0.05)$ lower in the BR group than in the $\mathrm{C}$ group, whereas AOM alone caused a slight decrease in colonic $\mathrm{pH}$. BR significantly reduced colonic $\mathrm{pH}$ with or without AOM.

\section{Effect of barley Rihane on the incidence of aberrant crypt foci in the rat colon induced by azoxymethane}

The effect of $\mathrm{BR}$ on AOM-induced ACF development in rats is summarised in Table 4. The results showed that there were no ACF in the colon of normal rats. However, colonic $\mathrm{ACF}$ appeared in all rats that received $\mathrm{AOM}$. In the $\mathrm{C} / \mathrm{AOM}$ and BR/AOM groups, the incidence of ACF was $100 \%$. The results showed that the number of $\mathrm{ACF} / \mathrm{colon}$ was lower $(P<0.05)$ in rats fed the BR/AOM diet compared with rats fed the $\mathrm{C} / \mathrm{AOM}$ diet. Indeed, $\mathrm{BR}$ gave an important reduction (44\%) in the total number of ACF/colon.

\section{Histological classification of aberrant crypt foci}

The incidence of dysplastic crypt formation in each group is shown in Table 4. The results of the carcinogenesis

Table 3. Final body weight, body-weight gain, food intake, colon weight and colon content in the different groups (control (C), C/azoxymethane (AOM), barley Rihane (BR) and BR/AOM)

(Mean values with their standard errors, $n 10)$

\begin{tabular}{|c|c|c|c|c|c|c|c|c|}
\hline \multirow[b]{2}{*}{ Parameters } & \multicolumn{2}{|c|}{$C^{*}$} & \multicolumn{2}{|c|}{$\mathrm{C} / \mathrm{AOM}+$} & \multicolumn{2}{|c|}{ BR } & \multicolumn{2}{|c|}{ BR/AOM§ } \\
\hline & Mean & SEM & Mean & SEM & Mean & SEM & Mean & SEM \\
\hline Final body weight (g) & $241 \cdot 0^{a}$ & $6 \cdot 00$ & $231 \cdot 0^{\mathrm{a}}$ & $6 \cdot 19$ & $217 \cdot 0^{\mathrm{b}}$ & 6.44 & $221 \cdot 0^{a}$ & 5.99 \\
\hline Body-weight gain (\%) & $60 \cdot 09^{a}$ & 3.99 & $53.92^{\mathrm{a}}$ & $4 \cdot 51$ & $45 \cdot 04^{b}$ & 4.93 & $47 \cdot 43^{b}$ & 3.50 \\
\hline Food intake $(\mathrm{g} / \mathrm{d})$ & $17 \cdot 0$ & 1.03 & $17 \cdot 0$ & 0.79 & $19 \cdot 0$ & 1.40 & $18 \cdot 0$ & 0.57 \\
\hline \multicolumn{9}{|l|}{ Weights (g) } \\
\hline Colon & $8 \cdot 23^{a}$ & 0.03 & $6 \cdot 69^{b}$ & 0.04 & $8.97^{c}$ & 0.06 & $10 \cdot 82^{d}$ & 0.03 \\
\hline Colon digesta & $4 \cdot 87^{a}$ & 0.04 & $4 \cdot 11^{b}$ & 0.06 & $5.49^{c}$ & 0.06 & $6 \cdot 03^{d}$ & 0.06 \\
\hline Colonic wall & $3.35^{a}$ & 0.02 & $2 \cdot 57^{b}$ & 0.05 & $3.48^{\mathrm{c}}$ & 0.01 & $4 \cdot 78^{d}$ & 0.05 \\
\hline Colonic pH & $6 \cdot 84^{\mathrm{a}}$ & 0.01 & $6 \cdot 75^{a}$ & 0.03 & $5 \cdot 76^{c}$ & 0.04 & $6 \cdot 38^{d}$ & 0.03 \\
\hline
\end{tabular}

a,b,c,d Mean values with unlike superscript letters were significantly different $(P<0.05)$.

${ }^{*}$ Rats fed the $\mathrm{C}$ diet.

† Rats fed the $\mathrm{C}$ diet and treated with AOM.

$\ddagger$ Rats fed the BR diet.

$\S$ Rats fed the BR diet and treated with AOM. 
Table 4. The effect of barley Rihane (BR) on the incidence of aberrant crypt foci (ACF) in the rat colon induced by azoxymethane (AOM)

(Mean values with their standard errors, $n 10$ )

\begin{tabular}{lcccclcl}
\hline Group & Treatment & No. of rats & Incidence (\%) & No. of ACF/colon & SEM & Morphology & $P$ \\
\hline 1 & C $^{*}$ & 10 & 0 & 0 & 0 & 0 & 0 \\
2 & C/AOM† & 10 & $10 / 10(100)$ & $188 \cdot 7^{\mathrm{a}}$ & 3.57 & Severe dysplasia & 0.05 \\
3 & BR & 10 & 0 & 0 & 0 & 0 & 0 \\
4 & BR/AOM§ & 10 & $10 / 10(100)$ & $83 \cdot 46^{\mathrm{b}}$ & 7.86 & Moderate dysplasia & 0.05 \\
\hline
\end{tabular}

C, control.

a,b Mean values with unlike superscript letters were significantly different $(P<0.05)$.

${ }^{*}$ Rats fed the $\mathrm{C}$ diet.

† Rats fed the $\mathrm{C}$ diet and treated with AOM.

$\ddagger$ Rats fed the BR diet.

$\S$ Rats fed the BR diet and treated with AOM.

experiment, 12 weeks after the AOM treatment, demonstrated that in rats fed the BR diet and treated with $\mathrm{AOM}$, there was a significant reduction $(P<0.05)$ in the severity of dysplasia compared with the C/AOM group (Fig. 2(D) and (B)). Colon sections from these rats showed a slight or moderate dysplasia, whereas those from rats of the C/AOM group showed severe dysplasia or carcinoma in situ. However, rats in the $\mathrm{C}$ and $\mathrm{BR}$ groups showed a normal morphology (Fig. 2(A) and (C)).
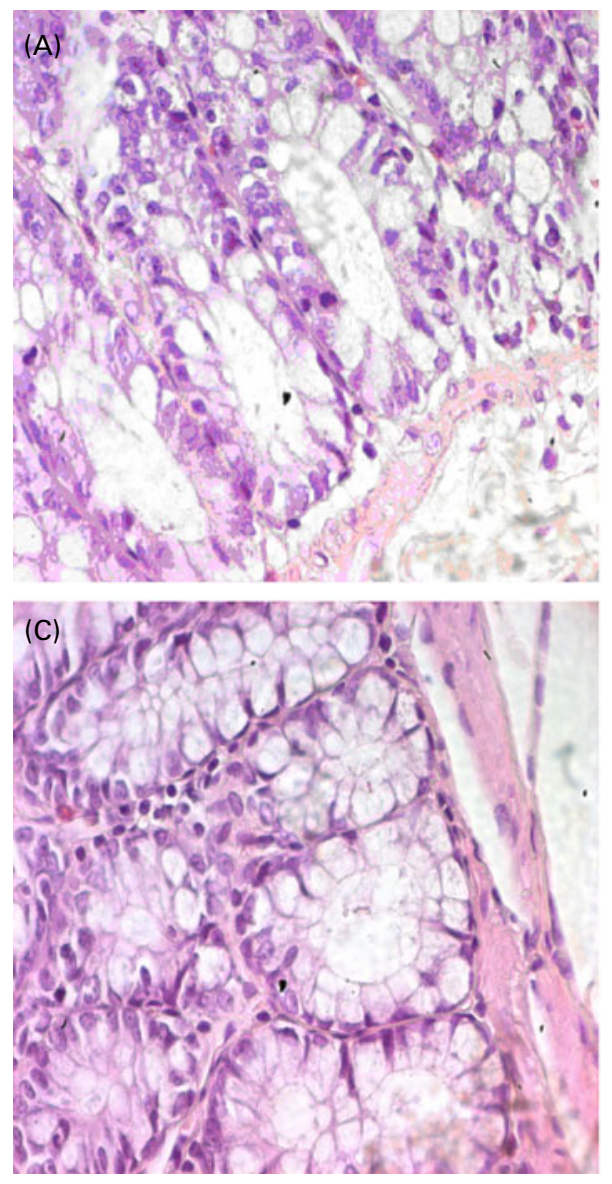

Fig. 2. Morphological evaluations of aberrant crypt foci in different groups of rats for the presence and degree of dysplasia (haematoxylin and eosin staining, $400 \times$ ): (A) histological section from the control (C) group indicating normal morphology, (B) from the C/azoxymethane (AOM) group indicating severe dysplasia or carcinoma in situ (the wall of the colon has thickened mucosa and proliferated glands lined by the cells with hyperchromatic, pseudostratified nuclei), (C) from the barley Rihane (BR) group indicating normal architecture and (D) from the BR/AOM group indicating slight or moderate dysplasia. $\rightarrow$, Increased number of mitoses; $\mathbf{\Lambda}$, crypts being moderately basophilic and more hypercellular, A, crypts being strongly basophilic and very hypercellular. (A colour version of this figure can be found online at http://www.journals.cambridge.org/bjn)

\section{Bacterial diversity}

The gels resulting from PCR amplification of conserved bacteria domain sequences followed by TTGE (evaluation of total bacterial diversity) were examined for bands at seventy-five possible positions (Fig. 3). The occurrence of bands in the four groups was as follows: fifteen bands in the $\mathrm{C}$ group, nineteen bands in the $\mathrm{C} / \mathrm{AOM}$ group, twenty-three bands in the BR group and seventeen bands in the BR/AOM

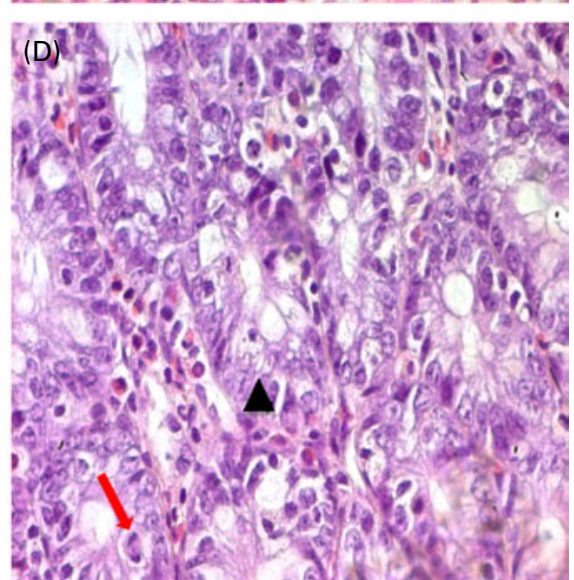




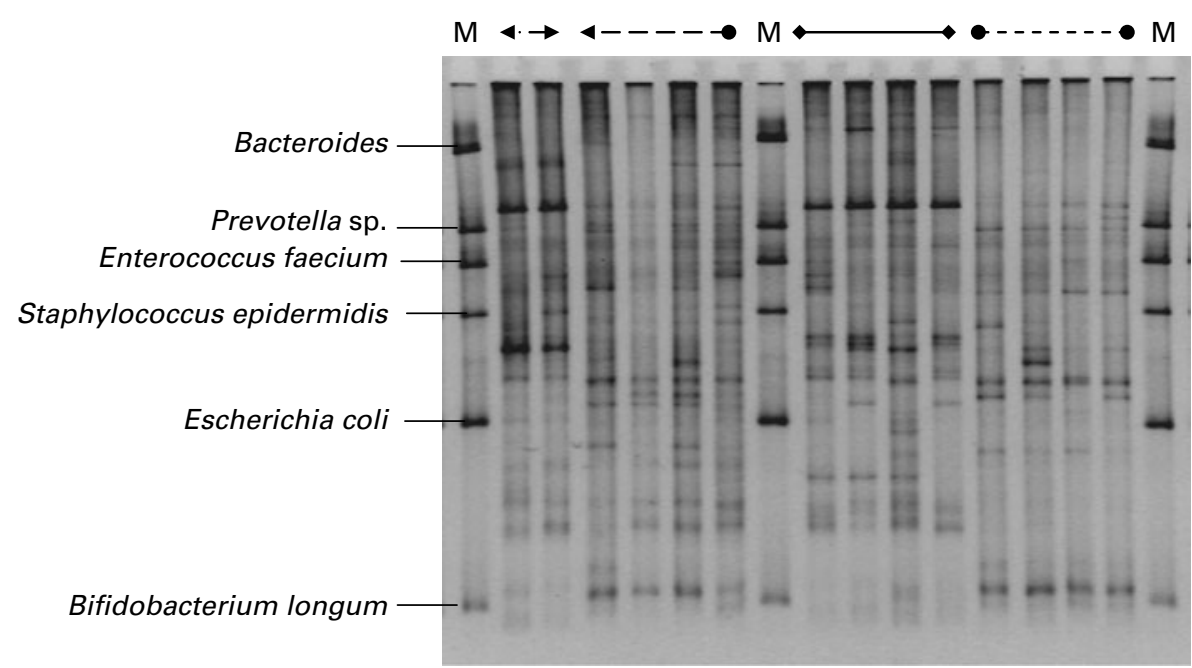

Fig. 3. Temporal temperature gradient gel electrophoresis gel showing bands obtained by the electrophoresis of PCR products from rat colonic content using primers targeted at conserved bacterial 16S ribosomal DNA sequences representative of domain bacteria. Lanes at the left and right extremes represent DNA marker (M). Bands 63 (Escherichia) and 95 (Bifidobacterium) are marked. C, Control; AOM, azoxymethane; BR, barley Rihane. C (• - - - - •), rats fed the C diet; C/AOM $(\bullet$ ), rats fed the C diet and treated with AOM; BR $(\triangleleft--\bullet)$, rats fed the BR diet; BR/AOM $(\triangleleft \cdot \rightarrow)$, rats fed the BR diet and treated with AOM.

group. The TTGE profiles of the BR group showed that bacterial biodiversity was higher than that in C group. Several bands corresponding to the Bifidobacterium genus (band 95) were found in the BR profile. This result showed that BR favoured the Bifidobacterium biodiversity. However, several bands corresponding to E. coli (band 63) were found in the $\mathrm{C} / \mathrm{AOM}$ profile. This result showed the AOM favoured the dominance of $E$. coli.

All PCR-TTGE profiles obtained from each gel were compared and the results were plotted as a dendrogram after calculating the Dice coefficient to assess the similarities between them (Fig. 4). We noted a strong similarity of $74 \%$ between the species of the BR/AOM group compared with the other groups, but this percentage did not reach the threshold of positive similarity ( $>98 \%)$. Comparison of similarity coefficients showed a species variability of colonic microbiota between the different groups. In addition, we showed inter-individual variability within the same group. This similarity is affected by the diet BR and AOM.

\section{Bacteria, bifidobacteria and enterobacteria quantification}

Results for total bacteria, bifidobacteria and enterobacteria in colonic samples using real-time PCR are shown in Fig. 5. The number of total bacteria in all the experimental groups (BR, $\mathrm{C} / \mathrm{AOM}$ and $\mathrm{BR} / \mathrm{AOM})$ increased $(P<0.05)$ compared with the $\mathrm{C}$ group. The number of bifidobacteria decreased in the $\mathrm{BR}$ group compared with the $\mathrm{C}$ group. However, the enterobacteria number in colonic content was significantly increased $(P<0.05)$ in the BR group compared with the C group.

\section{Discussion}

We tested the hypothesis that DF would reduce AOM-induced formation of colonic ACF in rats. ACF are considered to be possible precursor lesions for colon cancer and are regarded as a short-term marker of colon carcinogenesis in rodents and human subjects ${ }^{(20)}$. In the present study, colons were examined for ACF 12 weeks after the first injection of AOM. Data from ACF incidence indicated that all rats treated with AOM developed ACF. The results demonstrated that the DF of BR may decrease AOM-induced ACF development. The reduction in the incidence of $\mathrm{ACF}$ in rats in the $\mathrm{BR}$ group may be due to the induction of apoptosis in the colonic crypts. These results support those of previous investigation by Alabaster et al. ${ }^{(21)}$ which reported that the DF of wheat reduced the total number of $\mathrm{ACF}$ in the rat colon. The finding of a reduction in the largest lesions may be most pertinent in terms of eventual development of colon tumours. Besides, the decrease in the numbers of ACF suggests that DF may inhibit the growth of ACF. The protective effects of DF on ACF development depend on the nature and source of the fibre,

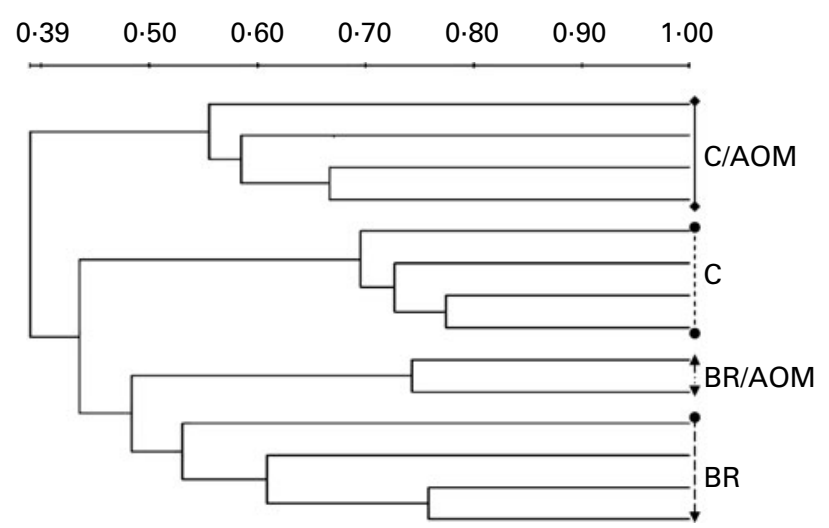

Fig. 4. Dendrogram representing the degree of relatedness among the $16 \mathrm{~S}$ ribosomal DNA banding patterns of the different groups. C, Control; AOM, azoxymethane; BR, barley Rihane. C (- - - $)$, rats fed the $\mathrm{C}$ diet; C/AOM $(\bullet)$, rats fed the $\mathrm{C}$ diet and treated with $\mathrm{AOM}$; BR $(\triangleleft--\rightarrow)$, rats fed the BR diet; BR/AOM $(\triangleleft \rightarrow)$ ), rats fed the BR diet and treated with AOM. 


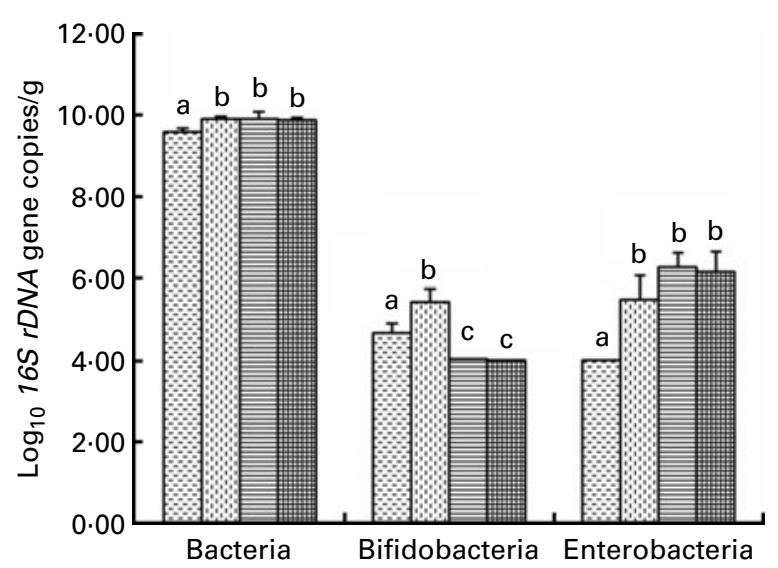

Fig. 5. Effect of the diet supplemented with barley Rihane (BR) on numbers of bacteria, bifidobacteria and enterobacteria in azoxymethane (AOM)treated rats compared with the control $(C)$. Values are means of ten rats, with standard errors represented by vertical bars. ${ }^{a, b, c}$ Mean values with unlike letters were significantly different $(P<0.05)$. $C(E)$, rats fed the $C$ diet; C/AOM $(⿷)$, rats fed the $C$ diet and treated with $A O M ; B R(\equiv)$, rats fed the $\mathrm{BR}$ diet; BR/AOM (䧃), rats fed the BR diet and treated with AOM.

as studied by Reddy et $a l .{ }^{(22)}$. After the quantification of ACF was made, the same tissue was used for ACF characterisation. According to Pretlow et $a l^{(23)}$ and McLellan et al. ${ }^{(24)}$, evaluation of haematoxylin and eosin-stained sections of ACF from rodents reveals a wide range of histology from minor atypia to severe dysplasia. According to Shpitz et al. ${ }^{(25)}$, dysplasia is considered as a feature of neoplasia, although it is not sufficient to define cancer. ACF have been classified as dysplastic, based primarily on morphological characteristics $^{(26)}$. Nuclear atypia and/or dysplasia increases as a function of time following a dose of carcinogen, but, again, there is a great heterogeneity ${ }^{(26)}$. In the present study, we found an overall significant reduction in dysplastic changes in the $\mathrm{BR} / \mathrm{AOM}$ group. The $\mathrm{DF}$ of $\mathrm{BR}$ probably slowed down the development of abnormality and consequently the advancement towards neoplasticity for the ACF observed. Therefore, it suggests that the barley variety used may potentially modulate colon cancer risk from an early stage.

The indigestible fibre components of barley, especially $\beta$-glucan, as well as resistant starch, progress through the digestive tract into the large intestine. Fermentation of this material by microflora then occurs, resulting in the formation of SCFA, especially butyrate and propionate ${ }^{(27)}$. The benefits of these fatty acids in the large intestine are healthy colonic mucosa and provision of an energy source for epithelial cells ${ }^{(28)}$. Dongowski et $a l^{(29)}$ investigated the effects of a high-amylose barley compared with maize starch, a highresistant starch commercial product and a $\mathrm{C}$ diet with no barley. These materials were extruded to prepare experimental diets for rats. All of the animals fed barley diets thrived better and had greater intestinal mass than controls. SCFA were higher in caecal and colon contents of animals fed the experimental diets. The more acid conditions indicated a smaller proportion of secondary bile acids, believed to be promoting factors in colon cancer. Bird et al. ${ }^{(30)}$ fed stabilised whole-grain barley flour from Himalaya 292, the high-amylose barley cited previously ${ }^{(31)}$, with two other barleys, and either wheat or oat bran to rats, to determine the effects of these feeds on intestinal SCFA. Although there were independent differences between animals fed different diets, colonic SCFA were consistently higher and $\mathrm{pH}$ was lower in those fed the Himalaya 292 barley than all other diets. Results were attributed to the greater RS content in this barley cultivar, due to its reduced amylopectin and increased amylose content as well as having a high $\beta$-glucan content. Biomarkers of bowel health in healthy subjects (faecal weight, faecal concentration of butyrate and SCFA excretion) were all significantly different between the groups and indicative of improved bowel health in subjects who consumed the barley diets. The beneficial health effects were attributed to the presence of resistant $\operatorname{starch}^{(30)}$.

These results showed that the BR diet decreased the colonic $\mathrm{pH}(P<0.05)$ compared with the $\mathrm{C}$ diet. Similar results were reported by Zoran et al. ${ }^{(32)}$ after feeding diets containing wheat bran. It was suggested that consumption of DF was associated with potentially beneficial changes in colon physiology after colonic $\mathrm{pH}$ reduction, which are in relation to the incidence of preneoplastic lesions and tumour risk in the colon. Dongowski et al. ${ }^{(29)}$ suggested that a reduction in colonic $\mathrm{pH}$ is a possible factor in the suppression of colon tumorigenesis. The present data also confirm the findings of other studies that intake of resistant starch decreases colonic $\mathrm{pH}$, which can be interpreted as improving bowel health and reducing the risk of developing colon cancer $^{\text {(33) }}$. Although lowering of the colonic $\mathrm{pH}$ is also usually considered to be protective, Thornton ${ }^{(34)}$ suggested that a very low $\mathrm{pH}$ may be a risk factor in carcinogenesis. DF produces high concentrations of SCFA. These reduce the $\mathrm{pH}$ in the colon, and values below 6.5 may result in a stimulation of epithelial cell proliferation with the subsequent enhancement of chemically initiated carcinogenesis. A high amount of cell proliferation is known to be a risk factor for colon cancer, presumably because it enhances the fixation of mutations.

Recent studies have revealed that the role of the microbiota was strongly related to the regulation of the incidence and progression of colon cancer. The colon is different from the other digestive organs, because it harbours an enormous number of coexisting microbiota ${ }^{(4)}$. The analysis of the colonic microbiota of forty rats using bacterial TTGE revealed a high inter-individual variability in the dominant microbiota, which increased with the BR diet. The TTGE profiles of the BR group showed that bacterial biodiversity was higher in the $\mathrm{BR}$ group than in $\mathrm{C}$ group. The present results suggest that the DF of BR can have long-term beneficial effects on the composition of colonic microbiota. The BR diet increased the biodiversity and number of total bacteria after 12 weeks. According to Venketeshwer et $a l^{(35)}$, intestinal microbiota was altered with the intake of DF after 2 weeks. Dongowski et $a{ }^{(29)}$ demonstrated that barley-rich diets providing $7 \cdot 0-12 \mathrm{~g} / 100 \mathrm{~g} \beta$-glucan in rats induced no significant changes in total aerobic micro-organisms and significant increases in total anaerobes only after 6 weeks of $\beta$-glucan consumption at doses $11-12 \mathrm{~g} / 100 \mathrm{~g}$. These authors showed that the effects of DF on colonic microbiota depend on the type, structure and concentration of the fibre. Abell et al. ${ }^{(36)}$ showed that 
the supplementation with specific dietary resistant starch leads to changes in faecal microbiota profiles that may be associated with improved bowel health.

Bifidobacteria numbers are depleted in rats fed BR. However, this variety has promoted biodiversity of this species. This is confirmed by Evdokia et al. ${ }^{(37)}$ who indicated that feeding a barley $\beta$-glucan diet induced a non-significant bifidogenic effect in Greek healthy adult volunteers. The DF of BR increased the total number of bacteria, but did not alter the composition of the microbiota in the colon. The presence of dietetic components in BR, especially $\beta$-glucan, could explain the decreased bifidogenic effect. This decrease could be due to factors intrinsic to the $\beta$-glucan composition and to their availability for bacterial attack.

AOM has favoured the dominance of $E$. coli. The present data also confirm the findings of other studies showing that E. coli are specifically involved in the activation of procarcinogens $^{(38)}$.

In conclusion, the results of the present experiments suggest that the DF of BR exert a preventive effect against AOM-induced rat ACF. The present study indicates that these compounds are potent factors to reduce colon cancer risk. More detailed BR studies concerning the mechanism of the onset of colon cancer, particularly regarding the changes in the microbiota (bacterial species identification by sequencing) and its metabolites on mucosal barrier function, are still required.

\section{Acknowledgements}

The present study received no specific grant from any funding agency in the public, commercial or not-for-profit sectors. The authors wish to thank Dr Badereddine Sriha and the staff of the Industry of Animal Nutrition-Tunisia 'Provital'. The authors' responsibilities were as follows: L. L. B., L. A., M. M. conceived and designed the study. H. B. S., M. E. F. M. H. and M. M. carried out the animal experiments, biochemical analysis, histological study and data analysis. P. P., F. M., I. M., A. S. and E. P. carried out the molecular biology experiments and participated in the interpretation of the results and preparation of the manuscript. All authors read and approved the final version of the manuscript. The authors have no conflict of interest to declare.

\section{References}

1. Aune D, Chan D, Lau R, et al. (2011) Dietary fibre, whole grains, and risk of colorectal cancer: systematic review and dose-response meta-analysis of prospective studies. BMJ 343, 1-20.

2. Oscarsson M, Anderson R, Salomonsson AC, et al. (1996) Chemical composition of barley samples focusing on dietary fibre components. J Cereal Sci 24, 161-170.

3. El Felah M \& Medimagh S (2005) Food barley in Tunisia. In Food Barley: Importance, Uses and Local Knowledge, pp. 29-35 [S Grando and HG Macpherson, editors]. Aleppo, Syria: ICARDIA.

4. Scott KP, Duncan SH \& Flint HJ (2008) Dietary fibre and the gut microbiota. Nutr Bull 33, 201-221.
5. McIntosh GH, LeLeu RK, Royle PJ, et al. (1996) A comparative study of the influence of differing barley brans on $\mathrm{DMH}$-induced intestinal tumors in male Sprague-Dawley rats. J Gastroenterol Hepatol 11, 113-119.

6. Chan CH, Cook D \& Stanners CP (2006) Increased colon tumor susceptibility in azoxymethane treated CEABAC transgenic mice. Carcinogenesis 27, 1909-1916.

7. Goldin BR (1988) Chemical indicators of colon tumors in animals. Prog Clin Biol Res 279, 319-333.

8. Bird RP (1995) Role of aberrant crypt foci in understanding the pathogenesis of colon cancer. Cancer Lett 93, 55-71.

9. Blaut M, Collins MD, Welling GW, et al. (2002) Molecular biological methods for studying the gut microbiota: the EU human gut flora project. Br J Nutr 87, 203-211.

10. Lahouar L, El Felah M, Mlik A, et al. (2008) Study of the chemical composition of various Tunisian varieties of barley (Manel, Rihane, Roho, Tej). Biologia-Tunisia 5, 94-95.

11. American Institute of Nutrition (1977) Report of the American Institute of Nutrition ad boc committee on standards for nutritional studies. J Nutr 107, 1340-1348.

12. Martha V, Lloyd TW, Louis S, et al. (2005) Inhibitory effects of nondigestible carbohydrates of different chain lengths on azoxymethane-induced aberrant crypt foci in Fisher 344 rats. Nutr Res 25, 859-868.

13. Norazalina S, Norhaizan ME, Hairuszah I, et al. (2010) Anticarcinogenic efficacy of phytic acid extracted from rice bran on azoxymethane induced colon carcinogenesis in rats. Exp Toxicol Pathol 62, 259-268.

14. Papanikolaou A, Wang QS, Papanikolaou D, et al. (2000) Sequential and morphological analyses of aberrant crypt foci formation in mice of differing susceptibility to azoxymethane-induced colon carcinogenesis. Carcinogenesis $\mathbf{2 1}$, $1567-1572$.

15. Godon JJ, Zumstein E, Dabert P, et al. (1997) Molecular microbial diversity of an anaerobic digestor as determined by small-subunit rDNA sequence analysis. Appl Environ Microbiol 63, 2802-2813.

16. Magne F, Abely M, Boyer F, et al. (2006) Low species diversity and high inter-individual variability in faeces of preterm infants as revealed by sequences of $16 \mathrm{~S}$ rRNA genes and PCR-TTGE profiles. FEMS Microbiol Ecol 57, 128-138.

17. Magne F, Hachelaf W, Suau A, et al. (2006) A longitudinal study of infant faecal microbiota during weaning. FEMS Microbiol Ecol 58, 563-571.

18. Deplancke B, Vidal O, Ganessunker D, et al. (2002) Selective growth of mucolytic bacteria including Clostridium perfringens in a neonatal piglet model of total parenteral nutrition. Am J Clin Nutr 76, 1117-1125.

19. Langendijk PS, Schut F, Jansen GJ, et al. (1995) Quantitative fluorescence in situ hybridization of Bifidobacterium spp. with genus-specific 16S rRNA-targeted probes and its application in fecal samples. Appl Environ Microbiol 61 , 3069-3075.

20. Bird RP \& Good CK (2000) The significance of aberrant crypt foci in understanding the pathogenesis of colon cancer. Toxicol Lett 112-113, 395-402.

21. Alabaster O, Tang Z \& Shivapurkar N (1997) Inhibition by wheat bran cereals of the development of aberrant crypt foci and colon tumours. Food Chem Toxicol 35, 517-522.

22. Reddy BS, Hirose Y, Cohen LA, et al. (2000) Preventive potential of wheat bran fractions against experimental colon carcinogenesis: implications for human colon cancer prevention. Cancer Res 60, 4792-4797.

23. Pretlow TP, O'Riordan MA, Somich GA, et al. (1992) Aberrant crypts correlate with tumor incidence in F344 rats 
treated with azoxymethane and phytate. Carcinogenesis $\mathbf{1 3}$, 1509-1512.

24. McLellan EA, Medline A \& Bird RP (1991) Sequential analyses of the growth and morphological characteristics of aberrant crypt foci: putative preneoplastic lesions. Cancer Res 51, 5270-5274.

25. Shpitz B, Bomstein Y, Kariv N, et al. (1996) Chemopreventive effect of aspirin on growth of aberrant crypt foci in rats. Int J Colorectal Dis 13, 169-172.

26. Nucci MR, Robinson CR, Longo R, et al. (1997) Phenotypic and genotypic characteristics of aberrant crypt foci in human colorectal mucosa. Hum Pathol 28, 1396-1407.

27. Topping DL \& Clifton PM (2001) Short-chain fatty acids and human colonic function: roles of resistant starch and nonstarch polysaccharides. Physiol Rev 81, 1031-1054.

28. Topping DL, Morell MK, King RA, et al. (2003) Resistant starch and health: Himalaya 292, a novel barley cultivar to deliver benefits to consumers. Starch/Stärke 55, 539-545.

29. Dongowski G, Huth M, Gebhardt E, et al. (2002) Dietary fiber-rich barley products beneficially affect the intestinal tract of rats. J Nutr 132, 3704-3714.

30. Bird AR, Flory C, Davies DA, et al. (2004) A novel barley cultivar (Himalaya 292) with a specific gene mutation in starch synthase IIa raises large bowel starch and SCFA in rats. J Nutr 134, 831-835.

31. Bird AR, Jackson M, King RA, et al. (2004) A novel highamylose barley cultivar (Hordeum vulgare var.) Himalaya
292 lowers plasma cholesterol and alters indices of largebowel fermentation in pigs. Br J Nutr 92, 607-615.

32. Zoran DL, Turner ND, Taddeo SS, et al. (1997) Wheat bran diet reduces tumor incidence in a rat model of colon cancer independent of effects on distal luminal butyrate concentrations. J Nutr 127, 2217-2225.

33. Clarke JM, Topping DL, Bird AR, et al. (2008) Effects of high-amylose maize starch and butyrylated high-amylose maize starch on azoxymethane-induced intestinal cancer in rats. Carcinogenesis 29, 2190-2194.

34. Thornton JR (1981) High colonic pH promotes colorectal cancer. Lancet 317, 1081-1083.

35. Venketeshwer R, Nalini S, Malcolm K, et al. (1994) Effect of fiber-rich foods on the composition of intestinal microflora. Nutr Res 14, 523-535.

36. Abell JGC, Christophersen CT, McOrist AL, et al. (2011) Dietary resistant and butyrylated starches have different effects on the faecal bacterial flora of azoxymethane-treated rats. Br J Nutr 105, 1480-1485.

37. Evdokia KM, Panopoulou N \& Turunen K (2010) Prebiotic potential of barley derived $\beta$-glucan at low intake levels: a randomised, double-blinded, placebo-controlled clinical study. Food Res Int 43, 1086-1092.

38. Cuevas-Ramos G, Claude R, Ingrid M, et al. (2010) Escherichia coli induces DNA damage in vivo and triggers genomic instability in mammalian cells. PNAS 107, 11537-11542. 